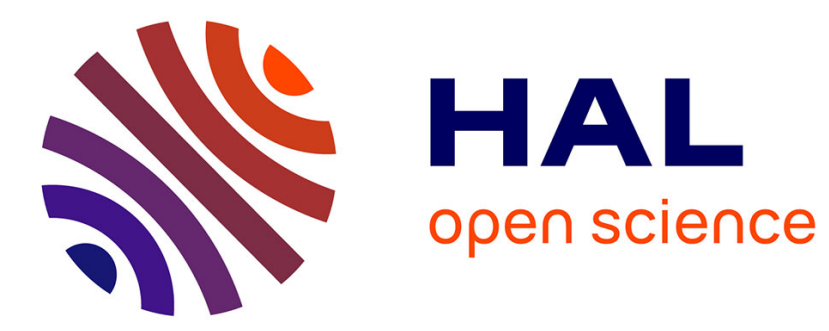

\title{
Effects of heat treatments on the microstructure and mechanical properties of a 6061 aluminium alloy
}

\author{
D. Maisonnette, M. Suery, D. Nelias, P. Chaudet, T. Epicier
}

\section{To cite this version:}

D. Maisonnette, M. Suery, D. Nelias, P. Chaudet, T. Epicier. Effects of heat treatments on the microstructure and mechanical properties of a 6061 aluminium alloy. Materials Science and Engineering: A, 2011, 528 (6), pp.2718-2724. 10.1016/j.msea.2010.12.011 . hal-00633941

\section{HAL Id: hal-00633941 \\ https://hal.science/hal-00633941}

Submitted on 7 Feb 2018

HAL is a multi-disciplinary open access archive for the deposit and dissemination of scientific research documents, whether they are published or not. The documents may come from teaching and research institutions in France or abroad, or from public or private research centers.
L'archive ouverte pluridisciplinaire HAL, est destinée au dépôt et à la diffusion de documents scientifiques de niveau recherche, publiés ou non, émanant des établissements d'enseignement et de recherche français ou étrangers, des laboratoires publics ou privés. 


\title{
Effects of heat treatments on the microstructure and mechanical properties of a 6061 aluminium alloy
}

\author{
D. Maisonnette ${ }^{\mathrm{a}}$, M. Suery ${ }^{\mathrm{b}}$, D. Nelias ${ }^{\mathrm{a}, *}$, P. Chaudet $^{\mathrm{a}}$, T. Epicier $^{\mathrm{c}}$ \\ a Université de Lyon, CNRS, INSA-Lyon, LaMCoS UMR5259, F-69621, France \\ b Université de Grenoble, SIMaP, UMR CNRS 5266, BP46, Domaine Universitaire, 38402 Saint Martin d'Hères Cedex, France \\ ' Université de Lyon, CNRS, INSA-Lyon, Mateis UMR5510, F-69621, France
}

\begin{abstract}
This paper describes the mechanical behavior of the 6061-T6 aluminium alloy at room temperature for various previous thermal histories representative of an electron beam welding. A fast-heating device has been designed to control and apply thermal loadings on tensile specimens. Tensile tests show that the yield stress at ambient temperature decreases if the maximum temperature reached increases or if the heating rate decreases. This variation of the mechanical properties is the result of microstructural changes which have been observed by Transmission Electron Microscopy (TEM).
\end{abstract}

Keywords: 6061 Aluminium alloy, Thermomechanical properties, Electron beam welding stress-strain curves, Yield stress, Hardening precipitates

\section{Introduction}

The study presented in this paper is concerned with the widely used 6061-T6 aluminium alloy. It is an age hardenable alloy, the mechanical properties of which being mainly controlled by the hardening precipitates contained in the material. When the material is subjected to a solution heat treatment followed by a quenching and a tempering treatment, its mechanical properties reach their highest level and become very good compared to other aluminium alloys. The as-obtained microstructure of the material is called T6 temper (tempering around $175^{\circ} \mathrm{C}$ ). Another interesting characteristic of the AA6061 is its good weldability. Because of these favorable properties, the AA6061 alloy is used in the transport and the public works domains (framework, pylon, handling equipment. ..) and also for complex structures assembled by welding [1-3].

The present work is part of the early qualifying study of a pressure vessel to be used in an experimental nuclear reactor. The approximate size of the vessel is five meters height with a diameter of about one meter. Several ferrules in AA6061-T6 should be assembled together by electron beam (EB) welding. The aim of the work presented in this paper is to evaluate the influence of the welding process on the mechanical properties of the material at room

\footnotetext{
* Corresponding author.

E-mail address: daniel.nelias@insa-lyon.fr (D. Nelias).
}

temperature. The change of mechanical properties is due to metallurgical phenomena such as dissolution, growth or coarsening of precipitates, which have been also observed.

It is commonly assumed that the generic precipitation sequence in $\mathrm{Al}-\mathrm{Mg}-\mathrm{Si}$ alloys is [4,5]:

$$
\mathrm{SSSS} \rightarrow \mathrm{GP} \rightarrow \beta^{\prime \prime} \rightarrow \beta^{\prime} \rightarrow \beta-\mathrm{Mg}_{2} \mathrm{Si}
$$

Here SSSS represents the super-saturated solid solution and GP stands for Guinier-Preston zones. The sequence (1) will be considered in this work. However, some authors give more details about this sequence [5-12] particularly Ravi and Wolverton [5] who gave a detailed inventory of the compositions of the phases contained in an Al-Mg-Si alloy. The compositions generally accepted for the most common precipitates are listed in Table 1.

According to the literature [6-9,13,14], the T6 temper of the 6XXX alloys involves very thin precipitates. They are $\beta^{\prime \prime}$ needleshaped precipitates oriented along the three $\langle 100\rangle$ directions of the matrix. Their size is nanometric and they are partially coherent.

The study presented in this paper includes High Resolution Transmission Electron Microscopy (HRTEM) observations of the investigated 6061-T6 alloy in order to characterize the precipitation state of the T6 temper. These observations will allow defining a precipitate distribution of reference for the initial alloy. From this initial state, thermal loadings are applied on specimens which are thereafter observed by TEM. The investigated thermal loadings will also be applied on tensile specimens in order to evaluate the variation of the resulting mechanical properties. 
Table 1

Compositions of the precipitates contained in $\mathrm{Al}-\mathrm{Mg}-\mathrm{Si}$ alloys.

\begin{tabular}{ll}
\hline Phase & Composition \\
\hline GP zone & $\mathrm{Mg}_{1} \mathrm{Si}_{1}$ \\
$\beta^{\prime \prime}$ & $\mathrm{Mg}_{5} \mathrm{Si}_{6}$ \\
$\beta^{\prime}$ & $\mathrm{Mg}_{9} \mathrm{Si}_{5}$ \\
$\beta$ & $\mathrm{Mg}_{2} \mathrm{Si}$ \\
\hline
\end{tabular}

For experimental convenience, the study will be limited to the solid state of the alloy. This means that the maximum temperature to be used is below $582^{\circ} \mathrm{C}$ (solidus temperature for the AA6061) and the phenomena occurring in the melting pool of the weld will not be taken into account here. Furthermore, the mechanical characterizations and microstructural observations will be carried out at room temperature after the thermal loading. This will allow the characterization of the material at various points of the Heat Affected Zone (HAZ) after welding (and not during the welding process). For that purpose, the required thermal loadings should reproduce the temperature evolution in the HAZ with high heating rates up to $200 \mathrm{~K} / \mathrm{s}$. An experimental device has been specifically developed to meet these requirements. At first, the design of the device will be briefly presented. Then, the results of the mechanical characterizations and microstructural observations will be presented and discussed.

\section{Experimental procedure}

\subsection{Experimental heating device}

The main purpose of the experimental heating device is to reproduce on a tensile specimen the thermal history encountered by each point of the heat affected zone during welding of the vessel. The highest temperature to be studied is thus $T=560^{\circ} \mathrm{C}$, very close to the solidus temperature of $582{ }^{\circ} \mathrm{C}$ which should not be reached. To do so, an accurate control of the temperature has been set up. Furthermore, the device should be able to reproduce the heating rate observed in the HAZ of an electron beam welding (up to $200 \mathrm{~K} / \mathrm{s}$ ). This heating rate has been evaluated by measuring it during an instrumented welding experiment. The second aim of the device is to apply a mechanical loading on a specimen in order to measure the mechanical properties of the material. The mechanical and thermal loadings have to be used simultaneously in order to perform tensile tests at high temperature for further study or to compensate for thermal expansion of the specimen during heating. Therefore, the experimental equipment includes a heating device and a mechanical testing machine.

\subsubsection{Design of the device}

A convenient method to heat aluminium alloys at very high rate is by Joule effect. Another way would be by induction heating but it is not efficient enough to obtain the required heating rate on aluminium alloys. For this reason, a resistive heating device has been designed and constructed. In order to measure the temperature of the specimen during heating, a thermocouple has been spot welded on the specimen surface. The strains are measured by means of an extensometer with ceramic tips.

The Joule heating device is a power supply, made of an electrical transformer and a thyristor bridge, providing a continuous current whose intensity is controlled by a thermal controller. Water cooled cables and clamping systems are used to connect the specimen to the heating device. A graphite resistor is added in series in order to increase the potential difference across the generator allowing a good temperature control.

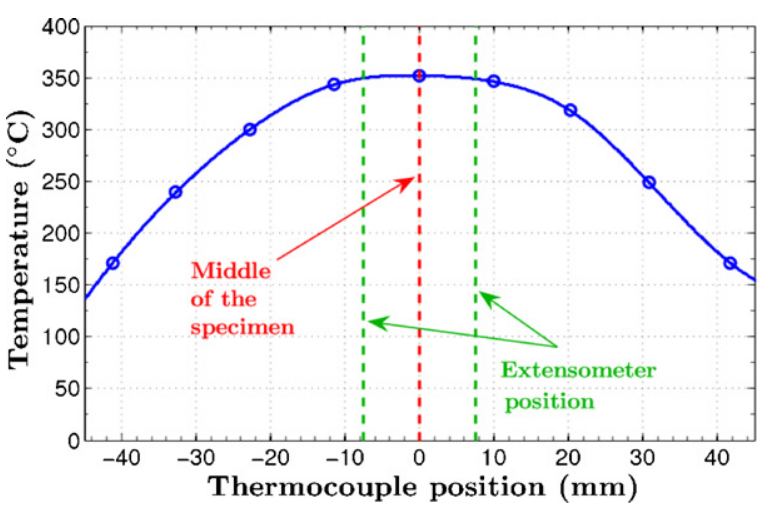

Fig. 1. Temperature distribution measured by thermocouples along the tensile specimen

\subsubsection{Specimen design}

A specimen heated by using Joule effect reacts as an electrical resistor. Its electrical resistance depends on the material electrical resistivity and the specimen shape which has to be optimized in order to reach the desired heating rate (up to $500 \mathrm{~K} / \mathrm{s}$ ). Moreover, the temperature must be uniform over the measurement area (between the extensometer tips) and the specimen volume should be large enough for the microstructure to be representative of the alloy in real structures.

A FEM simulation was performed to optimize the size and shape of the specimen. The used software, called Sysweld ${ }^{\circledR}$ was developed by ESI Group. The simulation is carried out by using an electro kinetic model [15]. The density $d$ and the thermal conductivity $K$ of the alloy were considered to vary with temperature. A parametric study shows that a diameter of $6 \mathrm{~mm}$ is required to obtain a heating rate up to $500 \mathrm{~K} / \mathrm{s}$. A specimen length of $100 \mathrm{~mm}$ is also required to have a low thermal gradient. Fig. 1 shows the temperature distribution in the specimen. The gradient has been measured with 10 thermocouples placed all over the length of a specimen peak-heated to $350^{\circ} \mathrm{C}$ at a heating rate of $15 \mathrm{~K} / \mathrm{s}$.

\subsubsection{Regulation set-up}

The experimental device has been designed to reach high heating rates. An accurate control of the temperature is required in order to avoid overshoots. To do so, a PID controller has been used [16-19]. The resulting thermal loading is slightly delayed but the heating rate is equal to the desired one. The cooling rate is maximum at the highest temperature (of the order of $23 \mathrm{~K} / \mathrm{s}$ at $500^{\circ} \mathrm{C}$ ) and decreases during cooling; it drops to about $6 \mathrm{~K} / \mathrm{s}$ when temperature becomes lower than $150^{\circ} \mathrm{C}$.

\subsection{Transmission Electron Microscopy}

The experimental device presented previously has been used to heat specimens for both mechanical measurements and TEM observations. Two types of microstructural observations have been carried out during this work. The first one is a detailed observation of the microstructure of the material in the T6 temper by means of HRTEM (High Resolution Transmission Electron Microscopy) and the second one by means of classical TEM to compare the microstructure of the alloy for three different states of precipitation. They were conducted on a JEOL 2010F microscope operating at $200 \mathrm{kV}$, which belongs to the Centre Lyonnais de Microscopie (CLYM) located at INSA Lyon (France).

TEM allows only very local observations so it was not intended to measure accurately the volume fraction of the precipitates; also not enough precipitates were analyzed to obtain an accurate mean radius. 
The samples used in TEM are thin lamellas. A disk with a thickness of about $200 \mu \mathrm{m}$ is extracted from the heated specimen by means of a diamond wire saw. Its diameter is then reduced by punching. The disk is thinned to electron transparency (thickness to about $200 \mathrm{~nm}$ or less) by electropolishing using an electrolytic bath composed of $20 \%$ of $\mathrm{HNO}_{3}$ in methanol. The bath is cooled at $-30{ }^{\circ} \mathrm{C}$ with liquid nitrogen [20]. A Precision Ion Polishing System (PIPS) is used in order to accomplish final thinning and cleaning by ion milling. Some EDX (Energy-dispersive X-ray spectroscopy) analysis were performed with an Oxford Instruments analyzer, using a nanoprobe (about $3 \mathrm{~nm}$ in diameter) in the TEM to estimate the composition of the precipitates in the $\mathrm{T} 6$ state.

\subsection{Mechanical characterization}

Tensile tests have been carried out at room temperature on specimens previously heated to peak temperatures of $200,300,400,500$ and $560^{\circ} \mathrm{C}$ with various heating rates $(0.5,5,15,50,200 \mathrm{~K} / \mathrm{s})$ in order to measure their mechanical properties. The thermal loadings are representative of the thermal histories encountered in EB welding.

Three parameters have been investigated. The first one is the maximum temperature reached during heating at a given heating rate $(r=15 \mathrm{~K} / \mathrm{s})$. The second one is the heating rate for a given maximum temperature $\left(T=400^{\circ} \mathrm{C}\right)$. The third one is the dwell time at $T=560^{\circ} \mathrm{C}$. This last study is not representative of a welding operation but will allow understanding the variation of the mechanical characteristics during holding at a given temperature which corresponds to the solution treatment of the alloy. For each test, the specimen is heated to the required temperature while compensating for thermal expansion, then it is cooled to room temperature and finally deformed until fracture at a strain rate of $10^{-2} \mathrm{~s}^{-1}$. During the test, for a strain close to $1.5 \%$, an unloading is performed to measure the elastic modulus.

\section{Results}

\subsection{HRTEM observations of the material in the T6 temper}

The aim of the HRTEM investigation on the AA6061-T6 is to measure the size of some hardening precipitates and to evaluate their composition in order to characterize the microstructure of the reference $\mathrm{T} 6$ state. The precipitates present in this state are hard to see owing to their very small size and because they are partly coherent with the aluminium matrix. HRTEM is thus mandatory to image the precipitates.

Fig. 2(a) shows a TEM picture at high magnification. Two needleshaped precipitates can be seen:

- The first one is oriented along the [0 0 1] direction. Its cross section is observed making its diameter measurable accurately. The measure gives a diameter of about $4 \mathrm{~nm}$.

- The second one is oriented along the [100] direction. It is observed lying in the thin foil.

The diffractogram, obtained by using Fourier transform, associated to the first precipitate is shown in Fig. 2(b). In addition to the $\left\{\begin{array}{lll}2 & 0 & 0\end{array}\right\}$ diffraction spots associated with the aluminium matrix, weak aligned spots prove that the atomic state is partially disordered as for pre- $\beta^{\prime \prime}$ phases.

At last, an EDX analysis carried out on the needle-shaped precipitates by means of a $3 \mathrm{~nm}$ probe gives an atomic ratio $X_{\mathrm{Mg}} / X_{\mathrm{Si}}=1.29$ (with a standard deviation of 0.3 ). This value is the average result of measurements on five precipitates.

\subsection{Classical TEM observations of the microstructural changes}

Following the detailed study of the T6 temper, the precipitates for various states were observed by means of classical TEM. The aim is to evaluate the evolution of the microstructure (size and volume fraction of precipitates) as a function of the thermal loading previously submitted to the material. Compared to HRTEM, classical TEM is a better way to evaluate the volume fraction because it allows a larger area to be observed at lower magnification. However classical TEM is worse than HRTEM to measure accurately the diameter of the precipitates because the images at high magnification are often fuzzy (a difficulty inherent to the diffraction contrast in conventional TEM).

\subsubsection{Comparison of three precipitation states}

The reference microstructure of the T6 temper is here compared to states observed after a heating up to $300^{\circ} \mathrm{C}$ and $400^{\circ} \mathrm{C}$ at a heating rate of $15 \mathrm{~K} / \mathrm{s}$ and no dwell time at the maximum temperature.

Fig. 3 shows three micrographs obtained from representative sample areas for the three investigated states. In the case of the specimen heated to $400^{\circ} \mathrm{C}$, some precipitates with a needle shape are present in the picture. These precipitates are very large, with length between 65 and $170 \mathrm{~nm}$ and a mean value of $112 \mathrm{~nm}$, and their diameter ranges between 5 and $11 \mathrm{~nm}$ with a mean value of $7.35 \mathrm{~nm}$. The mean values are calculated by taking into account ten precipitates observed on different pictures. However it should be mentioned that the precipitates could be cut by the sample preparation, consequently the length given above should be considered as indicative only. They will be used to compare the precipitation state.

In the two other cases, the precipitates are smaller. Their length is between 20 and $40 \mathrm{~nm}$ with a mean value of $29 \mathrm{~nm}$ for the T6 temper and between 15 and $40 \mathrm{~nm}$ with a mean value of $25 \mathrm{~nm}$ for the specimen heated to $300^{\circ} \mathrm{C}$. Their diameter ranges between 3.75 and $4.6 \mathrm{~nm}$ with a mean value of $4.45 \mathrm{~nm}$ for the T6 temper and between 2 and $4 \mathrm{~nm}$ with a mean value of $2.6 \mathrm{~nm}$ for the specimen heated to $300^{\circ} \mathrm{C}$.

\subsubsection{Precipitate volume fraction evaluation}

The precipitate size can be measured by means of TEM pictures. However, it is much more difficult to determine the precipitate volume fraction. Indeed, projections obtained by TEM correspond to volumetric observations but the thickness of the sample is not known accurately. In order to get a rough estimate of the precipitate volume fraction, TEM micrographs were compared to pictures obtained by modeling. A computer software has thus been developed in Matlab to simulate these images. Based on three simple parameters describing the precipitation state, the program can reproduce a needle-shaped precipitate distribution in a sample with a uniform thickness. The three parameters are the volume fraction $\left(f_{v}\right)$, the mean radius of the needle precipitates $\left(r_{\mathrm{avg}}\right)$ and their mean length $\left(L_{\mathrm{avg}}\right)$.

A Gaussian size distribution is arbitrarily assumed for the radius and the length with a variance of 1 and 36, respectively. The size distributions are discretized in one hundred classes of size. Once the thickness is fixed (illustrations will be given here for a $100 \mathrm{~nm}$ thick material), the total volume is calculated and an iterative algorithm increases step by step the number of precipitates in each class to obtain the volume corresponding to the desired $f_{v}$. The precipitates are then shown graphically on a $2 \mathrm{D}$ view by distributing them uniformly along the three $\langle 001\rangle$ directions of the Al-matrix, which corresponds to the viewing directions of the TEM micrographs shown in Figs. 2 and 3. Fig. 4 compares the precipitation state observed in the specimen heated to $300^{\circ} \mathrm{C}$ to two modeled states, the first one with a volume fraction of 3\% (Fig. 4(a)) and the second one with a volume fraction of $1.6 \%$ (Fig. $4(\mathrm{c})$ ). It clearly 


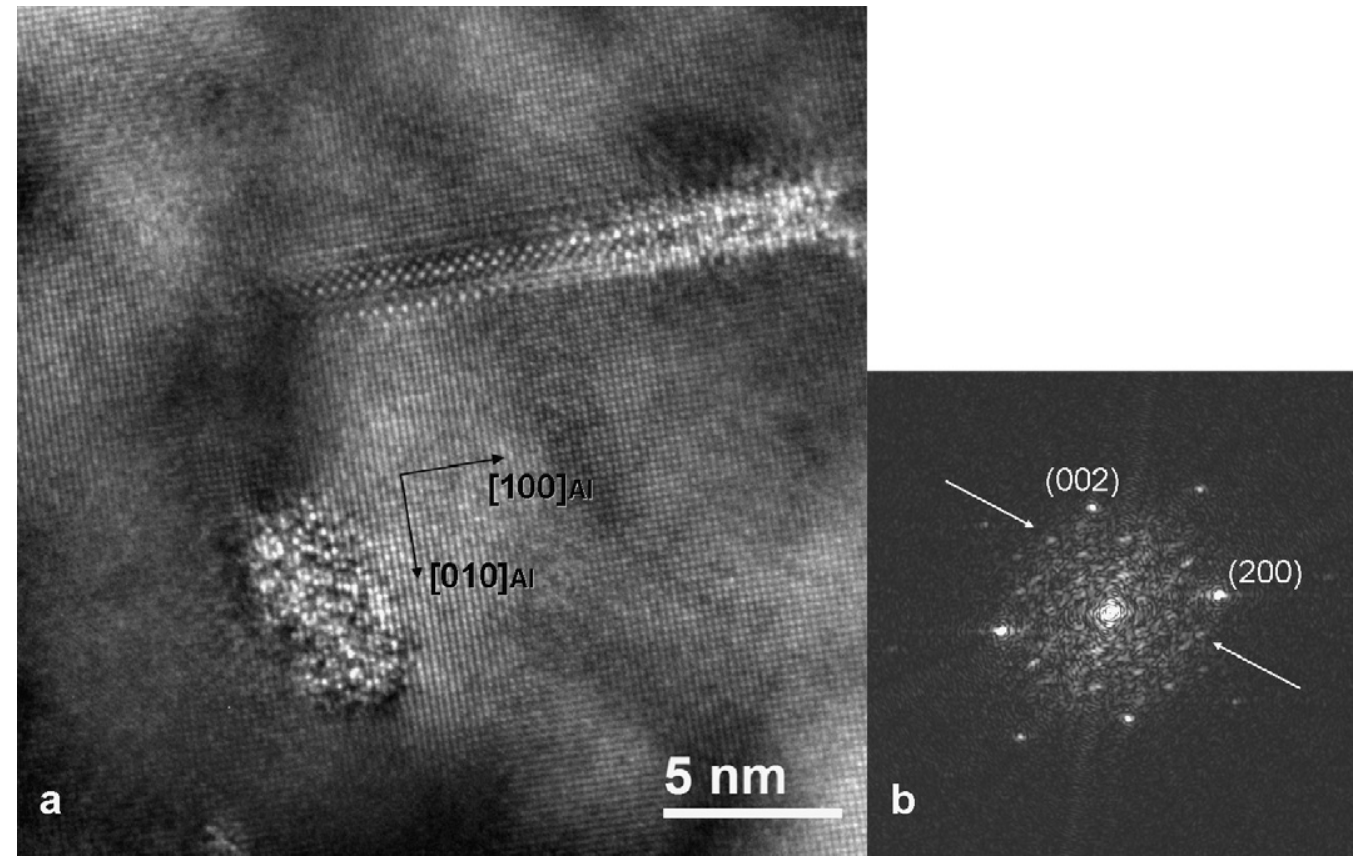

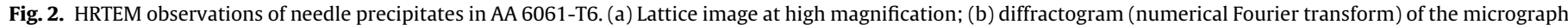
showing diffraction spots (arrows) arising from the precipitate in addition to the square lattice of the aluminium fcc phase along [0 01 ]

appears that $f_{v}=3 \%$ is not representative of the real precipitation state because it is too dense. The volume fraction of $1.6 \%$ is obviously closer to the volume fraction observed by TEM. The same type of study carried out for the two other investigated states gives a similar volume fraction.

\subsection{Mechanical characterization}

As indicated previously, three parameters have been investigated. The first one is the maximum temperature reached at a given heating rate $(r=15 \mathrm{~K} / \mathrm{s})$. The second one is the heating rate for a given maximum temperature $\left(T=400^{\circ} \mathrm{C}\right)$. The third one is the dwell time at $T=560^{\circ} \mathrm{C}$.

\subsubsection{Influence of the maximum temperature reached at constant} heating rate

The first mechanical study carried out at room temperature deals with the influence of the maximum temperature reached at a given heating rate on the mechanical properties of the AA6061T6. The maximum temperatures are $T=200,300,400,450,500$ and $560{ }^{\circ} \mathrm{C}$ at a heating rate of $r=15 \mathrm{~K} / \mathrm{s}$. The variations of temperature with time for these various thermal loadings are shown in Fig. 5. The tensile tests are then conducted at room temperature and the corresponding true stress-logarithmic strain curves are shown in Fig. 6 . The curves obtained for the heated specimens are compared with the curve obtained for the T6 temper without thermal loading (black continuous line). It is found that the thermal loading considerably influences the mechanical properties of the specimens except for a maximum temperature of $200^{\circ} \mathrm{C}$ for which the curve (not shown in Fig. 6) is exactly the same as that of the T6 sample. Indeed, the yield stress $\mathrm{Rp}_{0.2}$ decreases from $278 \mathrm{MPa}$ at $T=300^{\circ} \mathrm{C}$ to $70 \mathrm{MPa}$ at $T=500^{\circ} \mathrm{C}$. Increasing the temperature further to $560^{\circ} \mathrm{C}$, however, does not change the yield stress. Fig. 7 illustrates this $75 \%$ decrease of the yield stress when the maximum temperature is increased from 300 to $500{ }^{\circ} \mathrm{C}$. The measured values are compared to values from the literature [21] for which the maximum temper-
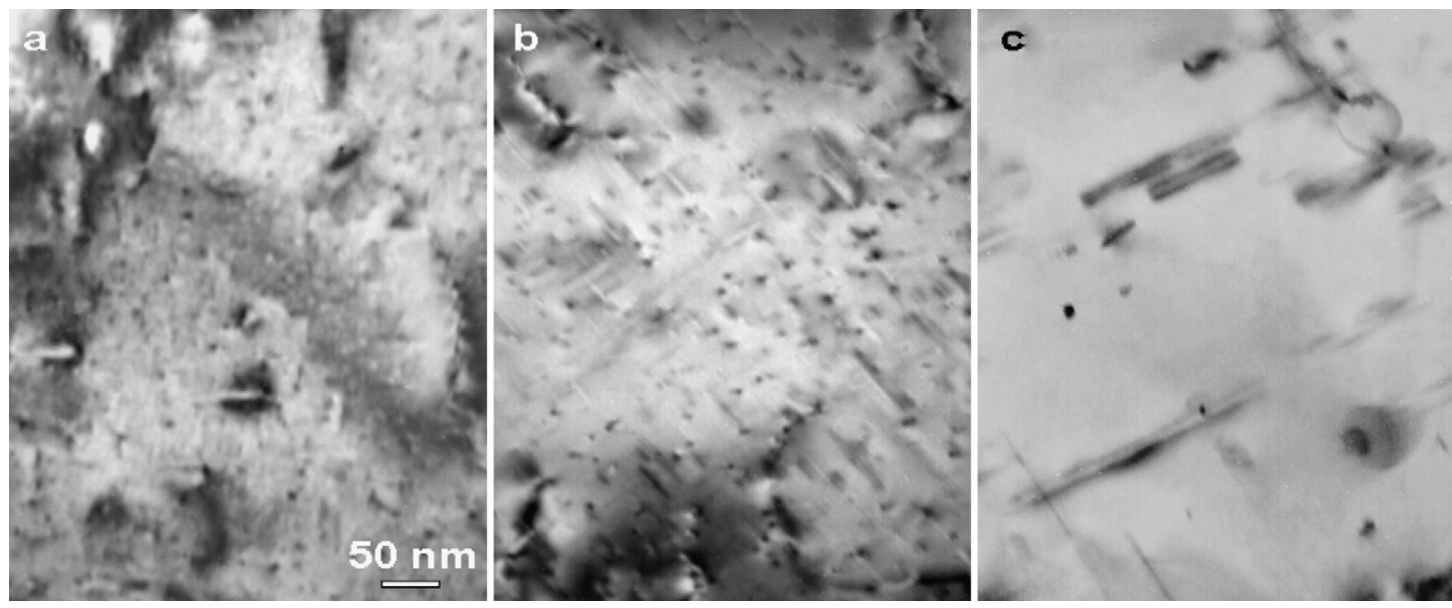

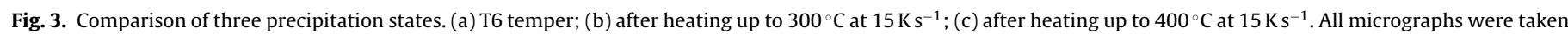
along a $\left\langle\begin{array}{lll}1 & 0 & 0\end{array}\right.$ zone-axis of the aluminium matrix. 
a

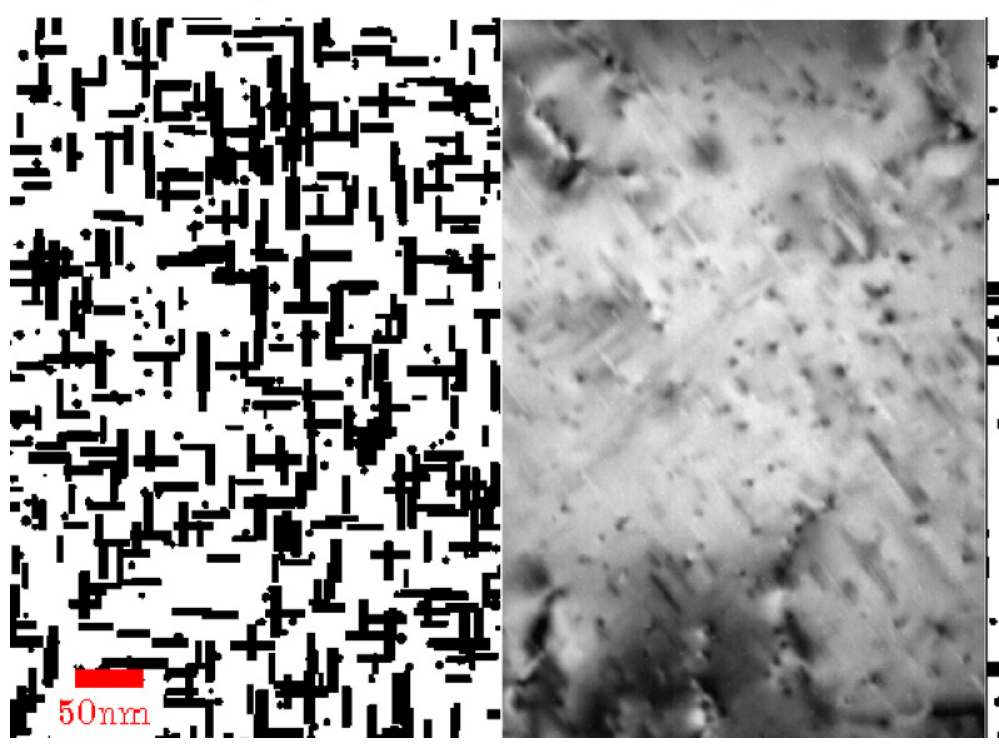

b

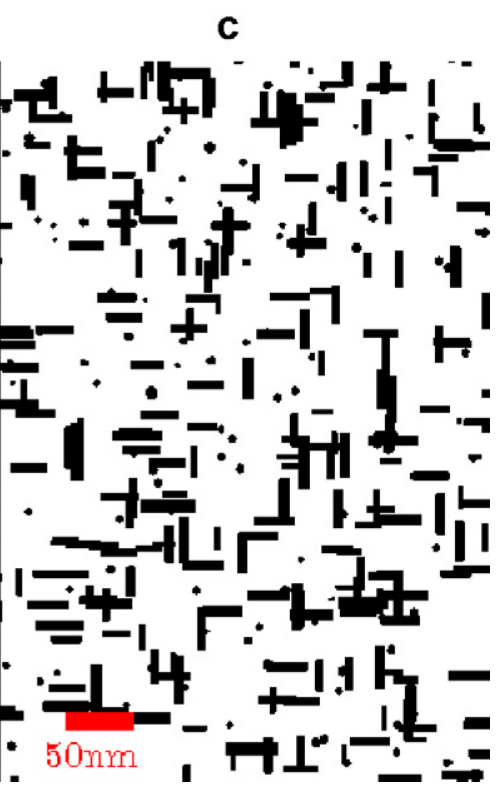

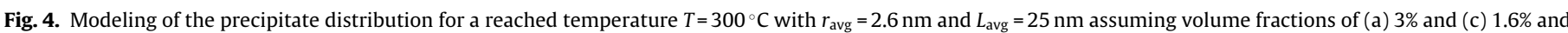

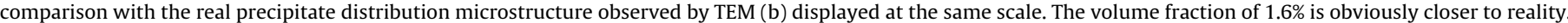

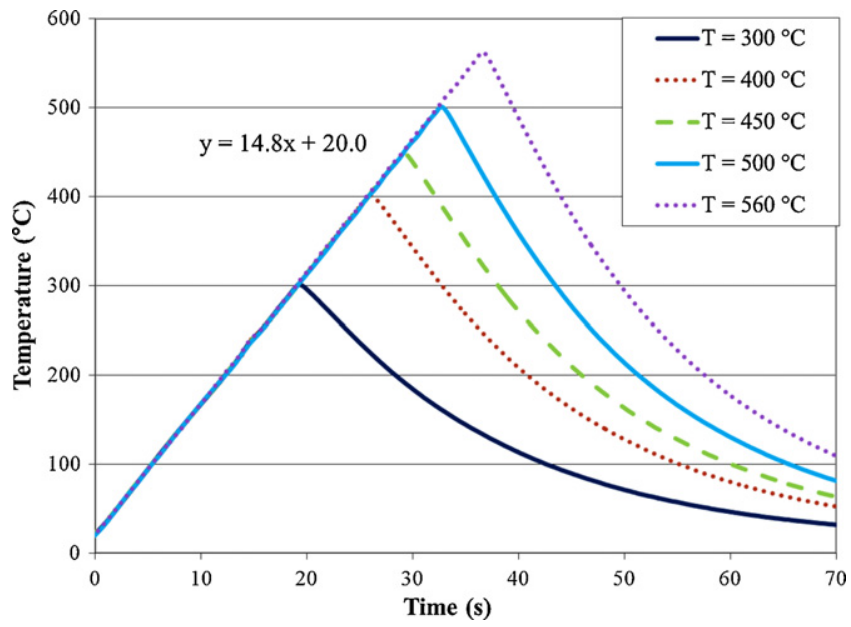

Fig. 5. Thermal loadings used for the study of the influence of the reached temperature.

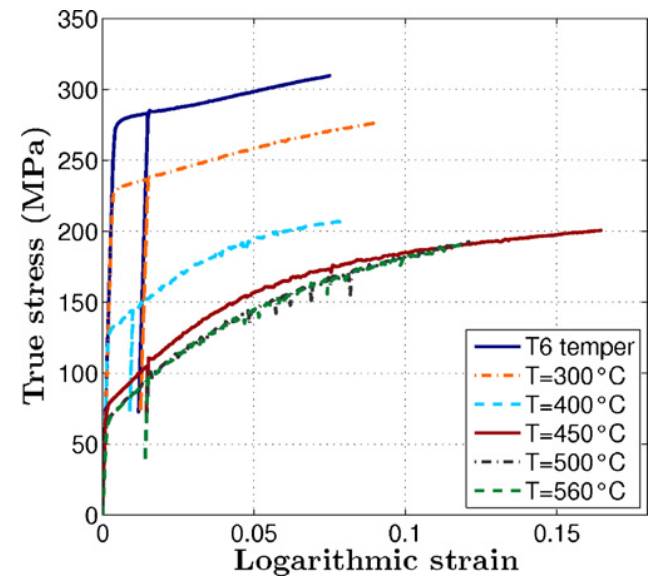

Fig. 6. True stress-logarithmic strain curves for temperatures up to $560^{\circ} \mathrm{C}$. ature has been held during $30 \mathrm{~min}$. It shows that the yield stress at ambient temperature is strongly dependent on the peak temperature reached during the thermal loading, without a dwell time at the highest temperature, for peak temperature higher than $200^{\circ} \mathrm{C}$. No data without dwell time at the maximum temperature have been found in the literature.

The Young modulus has been also measured for each specimen. It has been measured firstly at the origin of the stress-strain curve and then during the elastic unloading. A mean value is then calculated. It decreases from $68.7 \mathrm{GPa}$ for the T6 temper to $65.0 \mathrm{GPa}$ for the specimen heated to $560{ }^{\circ} \mathrm{C}$ which represents a $5.4 \%$ decrease.

\subsubsection{Influence of the heating rate}

The second mechanical study investigates the influence of the heating rate on the mechanical properties of the AA6061-T6. The maximum temperature applied here is $T=400^{\circ} \mathrm{C}$ and the studied heating rates are: $r=0.5,5,15,50$, and $200 \mathrm{~K} / \mathrm{s}$. The temperature variation obtained for $r=50 \mathrm{~K} / \mathrm{s}$ shows an overshoot of $8{ }^{\circ} \mathrm{C}$ which results in a slight decrease of the measured stress. Similarly, the temperature of the specimen heated with a heating rate of $r=200 \mathrm{~K} / \mathrm{s}$ did not reach $T=400^{\circ} \mathrm{C}$ but $T=362^{\circ} \mathrm{C}$. Consequently, the measured stress for this specimen would be higher than expected. The tensile tests give the true stress-logarithmic strain curves shown in Fig. 8. They show that the yield stress $\mathrm{Rp}_{0.2}$ decreases

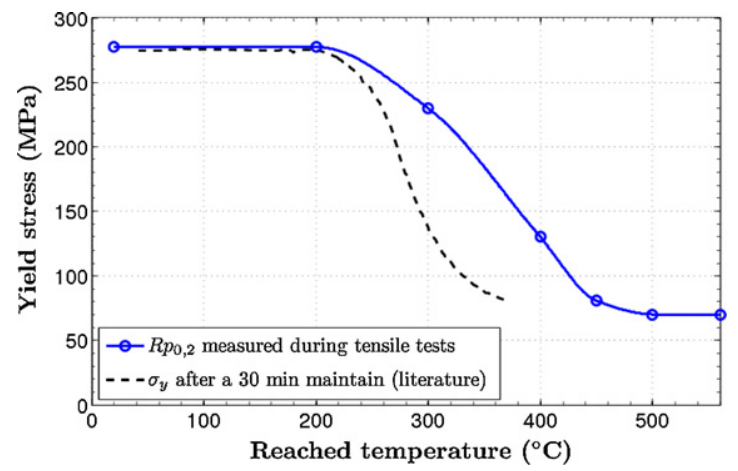

Fig. 7. Yield stress variation versus reached temperature from measurements (without temperature holding) and from the literature (with a 30 min dwell time). 


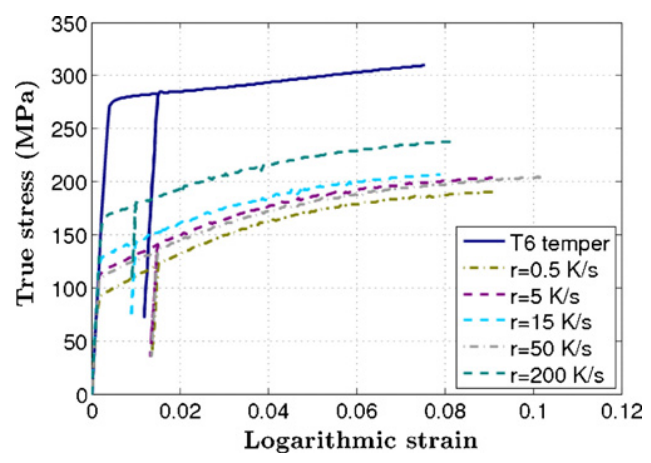

Fig. 8. True stress-logarithmic strain curves for various heating rates up to $200 \mathrm{~K} / \mathrm{s}$.

for every heated specimens compared to the T6 temper and the lower the heating rate is, the lower the yield stress of the material is. More precisely $\mathrm{Rp}_{0.2}$ decreases from $170 \mathrm{MPa}$ for a heating rate of $r=200 \mathrm{~K} / \mathrm{s}$ to $96 \mathrm{MPa}$ for a heating rate of $r=0.5 \mathrm{~K} / \mathrm{s}$. These values have not been compared with literature since no data dealing with the influence of the heating rate has been found.

\subsubsection{Influence of holding time at $560^{\circ} \mathrm{C}$}

The last mechanical study accomplished on the material is concerned with the influence of a holding time at high temperature before doing the tensile test at room temperature. This last study compares the mechanical properties of the AA6061-T6 after a heating at $T=560^{\circ} \mathrm{C}$ with and without a dwell time at this temperature. The temperature $T=560^{\circ} \mathrm{C}$ has been chosen because it is close to the solvus temperature of the $\beta$ phase in the $\alpha$ phase. The chosen dwell time is $t=30 \mathrm{~min}$ and the heating rate is $r=15 \mathrm{~K} / \mathrm{s}$. The mechanical properties obtained for both cases are strictly identical. This result indicates that the dwell time at $T=560^{\circ} \mathrm{C}$ does not influence the mechanical properties measured on the tested specimens.

\section{Discussion}

\subsection{Precipitation}

According to literature [5-9,13,14], the precipitates which are normally present in the T6 temper of the AA6061 alloy are very thin and their density is quite high. They are small needles of $\beta^{\prime \prime}$ (or pre- $\left.\beta^{\prime \prime}\right)$ type. They are oriented following the three $\langle 100\rangle$ matrix directions. Some authors $[6,10,22]$ have carried out a detailed study of the $\beta^{\prime \prime}$ phase. It appears that the $X^{\mathrm{Mg}} / X^{\mathrm{Si}}$ atomic ratio is very often close to 1 as reported in Table 1. However, other authors [23] managed to measure a $X^{\mathrm{Mg}} / X^{\mathrm{Si}}$ ratio higher than 1 for GP zones and co-clusters contained in an aged 6061. In addition, the observed precipitates are only partially coherent as for the pre- $\beta^{\prime \prime}$ phase. Based on these results, it can be assumed that the precipitates contained in the studied reference material are pre- $\beta^{\prime \prime}$ or $\beta^{\prime \prime}$ phases (although the $X^{\mathrm{Mg}} / X^{\mathrm{Si}}$ atomic ratio measured here to 1.29 is slightly higher than 1). Otherwise, Andersen et al. [6] measured needle precipitates with a size of about $4 \mathrm{~nm} \times 4 \mathrm{~nm} \times 50 \mathrm{~nm}$ for the $\beta^{\prime \prime}$ phase and $20 \mathrm{~nm} \times 20 \mathrm{~nm} \times 500 \mathrm{~nm}$ for the $\beta^{\prime}$ phase. Furthermore, Donnadieu et al. [8] measured the size of the precipitates contained in a $6065-\mathrm{T} 6$ alloy. They obtained a mean diameter of $2.86 \mathrm{~nm}$. By comparing these values to those presented in Sections 3.1 and 3.2 it can be assumed that the precipitates contained in the studied AA6061 after heating at $400^{\circ} \mathrm{C}$ are composed of the $\beta^{\prime}$ phase. On the contrary, the precipitates contained in the 6061-T6 and in the 6061 after a heating at $300^{\circ} \mathrm{C}$ are smaller. Therefore, the precipitates are probably remaining $\beta^{\prime \prime}$ precipitates for the 6061 alloy after heating at $300^{\circ} \mathrm{C}$.
In addition to that, large intermetallics are visible in the micrographs at low magnification, as shown in Fig. 9. The size of the intermetallics ranges from 50 to $300 \mathrm{~nm}$. These intermetallics formed during the elaboration of the material do not contribute to the hardening of the alloy. An energy dispersive X-ray spectrometry analysis (EDX) proved that their composition type is ( $\mathrm{Fe}-\mathrm{Cr}-\mathrm{Mn}-\mathrm{Si}$ ) and not (Al-Mg-Si) as for hardening precipitates. The structure of these intermetallics was not investigated further. However, it is important to note that the intermetallics do contain silicon, so that the corresponding quantity will not be available for hardening precipitation.

\subsection{Mechanical properties}

Fig. 6 showed that the behavior of the material after heating at $500^{\circ} \mathrm{C}$ is strictly identical to the behavior of the material after heating at $560{ }^{\circ} \mathrm{C}$. Thus, it can be assumed that the microstructure is the same in both cases. Furthermore, a tensile test carried out on a specimen heated to $560^{\circ} \mathrm{C}$ during 30 min gives exactly the same behavior. This behavior corresponds to the $\mathrm{O}$ temper. It is commonly accepted that a long holding time at $\mathrm{T}=560^{\circ} \mathrm{C}$ (solvus temperature of the $\beta$ phase in the $\alpha$ phase) is required to dissolve the precipitates. Comparison of the true stress-logarithmic strain curves obtained with and without dwell time shows that the mechanical properties are identical. This means that the dwell time at $T=560^{\circ} \mathrm{C}$ does not change the mechanical properties. The microstructure is therefore identical corresponding to the annealed state (or O temper) for which no precipitate is present in the material. This last result shows that for the heating rate and for the specimens used in this study, it is not necessary to apply a dwell time to reach the $\mathrm{O}$ temper. This conclusion is probably not valid in the case of a large structure since the peak temperature at each point within the material would depend on its distance from the closest surface. Another result of this investigation is that the heating rate has an influence on the mechanical properties. By using a higher heating rate, the $\mathrm{O}$ temper could not be obtained without a dwell time.

The hardening is due to the precipitates contained within the material. They hinder dislocation glide. For a given volume fraction, hardening is most effective if the precipitates are small (and therefore more numerous). These small precipitates have been observed by TEM for the T6 temper. This microstructure leads to more favorable mechanical properties than the other investigated states. The behavior observed here is quite close to the one observed by Zainul-Abdein et al. [24] on a 6056-T4. Then, the microstructure of the specimen heated to $300^{\circ} \mathrm{C}$ seems to be close to the one observed for the $\mathrm{T} 6$ temper, which explains the small difference of mechanical properties. If the maximum temperature is further increased, the yield stress $\mathrm{Rp}_{0.2}$ decreases significantly as shown in Fig. 7. The TEM observations show that this decrease is due to a strongly enhanced growth of the precipitates. The volume fraction of the precipitates remains identical so that the precipitate number is decreased. This results in a sharp decrease of the mechanical properties, as highlighted by the tensile tests.

Concerning the study of the influence of the heating rate, no microstructural observations have been carried out. However, Fig. 8 shows a decrease of the mechanical properties for every thermal loading up to $400^{\circ} \mathrm{C}$ compared to the mechanical properties of the T6 temper. This means that the material has encountered a microstructural change for every investigated heating rate. If the heating rate is very low, the microstructural changes as dissolution and growth of precipitates, have more time to occur. Consequently, less precipitates are present (for a constant volume fraction) and the mechanical properties are lower.

The Young modulus has been measured and it has been shown that it decreases slightly compared to the T6 state when 


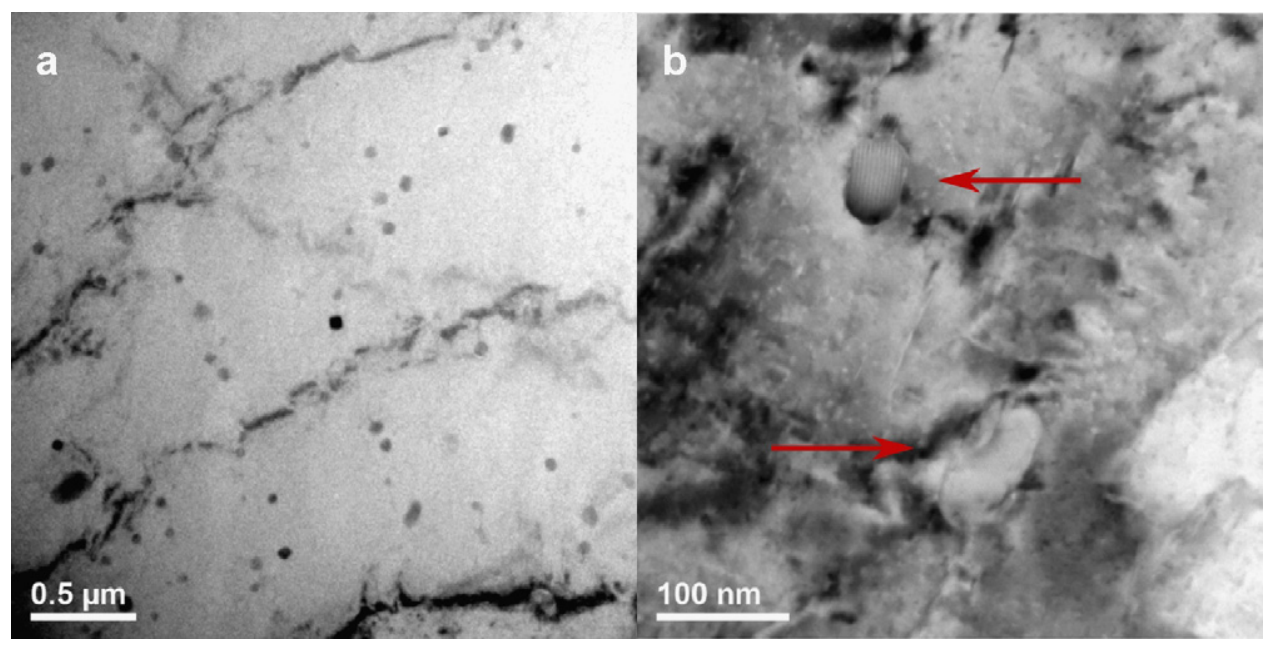

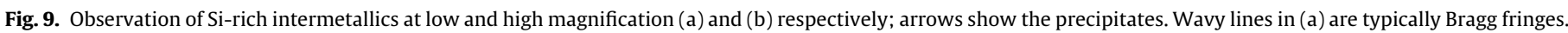

the material has been heated up to $560^{\circ} \mathrm{C}$. This decrease can be attributed to the dissolution of the hard precipitates which are present in the T6 state and which have a high Young modulus.

The results of the mechanical tests suggest that a decrease of the mechanical properties exists in the HAZ because of the dissolution and coarsening of the precipitates. This has indeed been measured by means of hardness tests which show that the decrease of the strength is more pronounced if the test position is closer of the melting zone.

\section{Summary}

The behavior of the AA6061-T6 has been studied at room temperature after previous controlled heating at various maximum temperatures by using different heating rates, and natural cooling to room temperature. These thermal loadings applied on tensile specimens are representative of the temperature variation encountered in the heat affected zone of an electron beam welding. The main results of this investigation are:

- In the T6 temper, numerous $\beta^{\prime \prime}$ precipitates are present in the shape of thin needles. Their mean diameter is $4.45 \mathrm{~nm}$ and their volume fraction is about $1.6 \%$. This volume fraction does not seem to vary much after heating.

- The precipitates evolve into $\beta^{\prime}$ phases during heating and their size increases significantly when the maximum temperature reached is $400^{\circ} \mathrm{C}$. Their mean diameter becomes $7.35 \mathrm{~nm}$ and their length increases.

- Tensile tests carried out to evaluate the influence of the maximum temperature and the heating rate on the strength of the material at room temperature shows that, at a heating rate of $15 \mathrm{~K} \mathrm{~s}^{-1}$ and for a maximum temperature of $400{ }^{\circ} \mathrm{C}$, the yield stress decreases if the peak temperature increases and the heating rate decreases. These variations are explained by coarsening of the precipitates.

- Heating up to 500 or $560^{\circ} \mathrm{C}$ at a heating rate of $15 \mathrm{~K} \mathrm{~s}^{-1}$ allows dissolution of the precipitates and reaching the $\mathrm{O}$ temper.

\section{Acknowledgements}

The authors wish to thank AREVA for the financial support and for the approval to publish the paper. The CLYM is gratefully acknowledged for the access to the microscope.

\section{References}

[1] International Aluminium Institute, Primary Aluminium Production http://www.world-aluminium.org, 22/09/08, 2008

[2] P. Voisin. Métallurgie extractive de l'aluminium. Techniques de l'ingénieur. Matériaux métalliques, M 2340 (1992) 2340.

[3] http://aluminium.matter.org.uk, 2010.

[4] J. Philibert, A. Vignes, Y. Bréchet, P. Combarde, Métallurgie-Du minerai au matériau, 2nd ed., Dunod Paris, 2002.

[5] C. Ravi, C. Wolverton, Acta Mater. 52 (14) (2004) 4213-4227.

[6] S.J. Andersen, H.W. Zandbergen, J. Jansen, C. Traeholt, U. Tundal, O. Reiso, Acta Mater. 46 (9) (1998) 3283-3298.

[7] G.A. Edwards, K. Stiller, G.L. Dunlop, M.J. Couper, Acta Mater. 46 (11) (1998) 3893-3904.

[8] P. Donnadieu, M. Roux-Michollet, V. Chastagnier, Philos. Mag. A 79 (6) (1999) 1347-1366.

[9] V. Massardier, T. Epicier, Mater. Sci. Forum 396-402 (2002) 851-856.

[10] M.A. van Huis, J.H. Chen, H.W. Zandbergen, M.H.F. Sluiter, Acta Mater. 54 (11) (2006) 2945-2955.

[11] R. Vissers, M.A. van Huis, J. Jansen, H.W. Zandbergen, C.D. Marioara, S.J. Andersen, Acta Mater. 55 (11) (2007) 3815-3823.

[12] M.A. van Huis, J.H. Chen, M.H.F. Sluiter, H.W. Zandbergen, Acta Mater. 55 (6) (2007) 2183-2199.

[13] M. Murayama, K. Hono, Acta Mater. 47 (5) (1999) 1537-1548.

[14] K. Matsuda S. Ikeno, T. Sato, HRTEM Study of Nano-Precipitation Phases in 6000 Series Aluminum Alloys, Science, Technology and Education of Microscopy: an Overview, 2003, pp. 152-162.

[15] E. Feulvarch, V. Robin, J.M. Bergheau, J. Mater. Process. Tech. 153 (2004) 436-441.

[16] K.J. Åström, C.C. Hang, P. Persson, W.K. Ho, Automatica 28 (1) (1992) 1-9.

[17] A.A. Voda, I.D. Landau, Automatica 31 (1) (1995) 41-53.

[18] T. Saito, J. Kawakami, S. Takahashi, T. Suehiro, H. Matsumoto, K. Tachibana, PID Control. Syst. (1990 February).

[19] D. Jacob, Techniques de l'ingénieur. Informatique industrielle S7418 (2004)

[20] J.C. Bravman, R.M. Anderson, M.L. McDonald, Mater. Res. Soc. Sympos. Proc. 115 (1988).

[21] R. Develay, Techniques de l'ingénieur (1992) M440.

[22] H.W. Zandbergen, S.J. Andersen, J. Jansen, Science 277 (5330) (1997) 1221

[23] J. Buha, R.N. Lumley, A.G. Crosky, K. Hono, Acta Mater. 55 (9)(2007) 3015-3024.

[24] M. Zain-ul-Abdein, D. Nélias, J.F. Jullien, A. Wagan, Mater. Des. 31 (9) (2010) 4302-4311. 